\title{
Mechanism study of isoflavones as an anti-retinoblastoma progression agent
}

\author{
Qifeng $\mathrm{Wu}^{1}$, He Bai ${ }^{2}$, Chu-Long Huang ${ }^{3}$, Yongming Zhang ${ }^{1,4}$, Xiayun Zeng ${ }^{4}$, Huan \\ Wan $^{1}$, Wen Zuo ${ }^{5}$, Hai-Ying Wang ${ }^{3}$, Yi-Xin Zeng ${ }^{1,5,6,7}$ and Yan-Dong Wang ${ }^{3}$ \\ ${ }^{1}$ National Cancer Center /Cancer Hospital, Chinese Academy of Medical Sciences and Peking Union Medical College, Beijing, \\ P. R. China \\ ${ }^{2}$ Department of Drug and Cosmetics Registration (Department of TCMs and Ethno- Medicines Supervision), China Drug and \\ Food Administration, Beijing, P. R. China \\ ${ }^{3}$ State Key Laboratory of Ophthalmology, Zhongshan Ophthalmic Center, Sun Yat-sen University, Guangzhou, P. R. China \\ ${ }^{4}$ Guangdong Wholewin Technology Ltd., Foshan, P. R. China \\ ${ }^{5}$ Beijing Hospital, Beijing, P. R. China \\ ${ }^{6}$ Department of Experimental Research, Sun Yat-sen University Cancer Center, Guangzhou, P. R. China \\ 7 State Key Laboratory of Oncology in Southern China, Guangzhou, P. R. China \\ Correspondence to: Yi-Xin Zeng, email: zengyx@sysucc.org.cn \\ Yan-Dong Wang, email: wangydsyj@163.com
}

Keywords: isoflavones; retinoblastoma; mTOR pathway; cyclin E1

Received: March 28, $2017 \quad$ Accepted: June 27, $2017 \quad$ Published: July 18, 2017

Copyright: Wu et al. This is an open-access article distributed under the terms of the Creative Commons Attribution License 3.0 (CC BY 3.0), which permits unrestricted use, distribution, and reproduction in any medium, provided the original author and source are credited.

\section{ABSTRACT}

Isoflavones, bioactive soy compounds, are known to exhibit anticancer activities. The present study investigated the anticancer activities of isoflavones on human retinoblastoma Y79 cells in vitro and in vivo. An MTT cell viability assay showed that the half maximal inhibitory concentration value of isoflavones against human retinoblastoma Y79 cells is $1.23 \pm 0.42 \mu \mathrm{mol} / \mathrm{I}$. Flow cytometry analysis indicated that isoflavones blocked G1/S progression. Western blot analysis demonstrated that the mammalian target of rapamycin (mTOR) pathway in Y79 cells was inhibited by isoflavones, with a concomitant decrease in cyclin E1, which accounted for the isoflavone-mediated $\mathbf{G 1}$ phase arrest. Isoflavones also inhibited human retinoblastoma growth in vivo; western blot analysis showed inhibition of mTOR and downregulation of cyclin E1 in an isoflavone-treated xenograft mouse model. Together, these results illustrate that isoflavones inhibit retinoblastoma tumour growth in vitro and vivo and that inactivation of the mTOR pathway and downregulation of cyclin E1 is involved in this action. The results of this study suggest that isoflavones could be tested as promising anti-retinoblastoma agent.

\section{INTRODUCTION}

Retinoblastoma is the most commonly occurring intraocular malignant tumour in infants and young children and originates from photoreceptor precursor cells [1]. Chemotherapy has become the most common eye-sparing treatment modality [2]. However, present chemotherapy treatments result in noteworthy complications including second primary malignancies (e.g. acute myeloid leukaemia, bone tumours and leiomyosarcomas); this effect is best described for topoisomerase inhibitors and alkylating agents $[3,4]$. Therefore, it is urgent to identify new therapeutic strategies to improve the clinical outcome of patients with retinoblastoma [5].

Genistein, daidzein, and glycitein are three major isoflavones which have some anti-cancer potential activities [6]. Genistein is cancer preventive phytochemical found in soy and other legumes [7-9] . Phase I clinical trials showed minimal toxicity in subjects treated with purified soy unconjugated isoflavone mixture 
[10]. Several studies have demonstrated that in vitro, genistein could prohibit the growth of various cancer cell lines including breast cancer cells [11], lung cancer cells [12], and colorectal cancer cells [9]. In addition, genistein could boost bacteriophage-mediated cancer cell killing [13]. Isoflavones are also helpful in the treatment of certain cancers by inhibiting tyrosine kinase activity and regulating Akt, mitogen-activated protein kinase and other signalling pathways [13-17]. The mammalian target of rapamycin (mTOR) is a serine-threonine kinase that regulates cell growth, proliferation, survival, angiogenesis and autophagy [18-20]. The mTOR pathway is commonly deregulated in human malignancies [21], including retinoblastoma [22]. A study revealed that activation of mTOR could modulate some molecules via retinoblastoma protein phosphorylated, which also told us the mTOR signal pathway may be directly related to some retinoblastoma proteins [23]; Then another research focused on RY-2f, a chemically synthesized isoflavone analog, that could inhibit ovarian tumorigenesis. Scientists in this study demonstrated that the mechanism of anti-cancer role was through PI3K/Akt/mTOR signaling pathway [24]. So these clues reminded us that isoflavones may be efficient to retinoblastoma.

In this study, we investigated whether there were anticancer activities of isoflavones in human retinoblastoma Y79 cells or not, and then we primarily studied its effects on the mTOR pathway in vitro and vivo.

\section{RESULTS}

\section{Effects of isoflavones on cell viability}

The cytotoxic effect of isoflavones on human retinoblastoma Y79 cells was determined by MTT cell viability assay. Isoflavones inhibited the growth of the cells, as shown in Figure 1B. The $\mathrm{IC}_{50}$ value was 1.23 $\pm 0.42 \mu \mathrm{mol} / \mathrm{L}$. The MTT assay showed that isoflavones were effective in blocking the proliferation of human retinoblastoma Y79 cells.

\section{Isoflavones induced G1 phase arrest}

Flow cytometry was used to distinguish between cells in different phases of the cell cycle. G1 phase arrest was seen in cells treated with isoflavones, as shown in Figure 2A. The proportions of cells in the G1 phase after treatment with $0,1,2$ and $4 \mu \mathrm{mol} / 1$ isoflavones were $44.53 \pm 5.03 \%, 52.37 \pm 5.24 \%, 63.73 \pm 8.01 \%$ and 73.24 $\pm 10.98 \%$, respectively (Figure 2B). Flow cytometry analysis showed that isoflavone treatment induced G1 arrest in a time-dependent manner which was associated with a concomitant significant.

\section{Isoflavones decreased phosphorylation of mTOR}

Inhibition of the mTOR pathway can block the cell cycle between G0 and G1; this is indicated by a marked decrease in G1 cyclins in retinoblastoma cells [25]. mTOR activity is markedly increased in tumour cells and mTOR is highly phosphorylated in these cells [26]. We therefore investigated the phosphorylation of mTOR in human retinoblastoma Y79 cells after treatment with isoflavones with western blot analysis. As shown in Figure 3A, phosphorylated mTOR (p-mTOR) decreased in isoflavone-treated Y79 cells compared with that in control cells, without significant changes in mTOR protein. Ribosomal S6K is the best known downstream effector of mTOR and is also a direct substrate of mTOR [27]. p-S6K also decreased in cells treated with isoflavones without significant changes in S6K protein (Figure 3A). These
A<smiles>O=C1c2c(O)cc(O)cc2OCC1c1ccc(O)cc1</smiles>

B

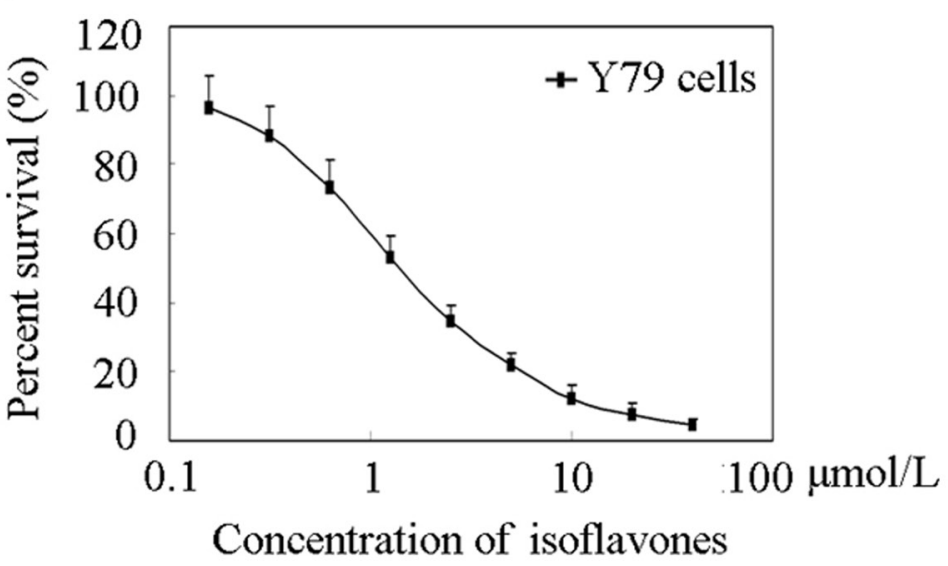

Figure 1: Effects of isoflavones on Y79 Cell proliferation. A. Chemical structure of isoflavones. B. Cell viability was determined with MTT assay. Cells were exposed to the indicated concentrations of isoflavones for $48 \mathrm{~h}$. Each point represents the mean \pm standard error of three independent experiments. 
A

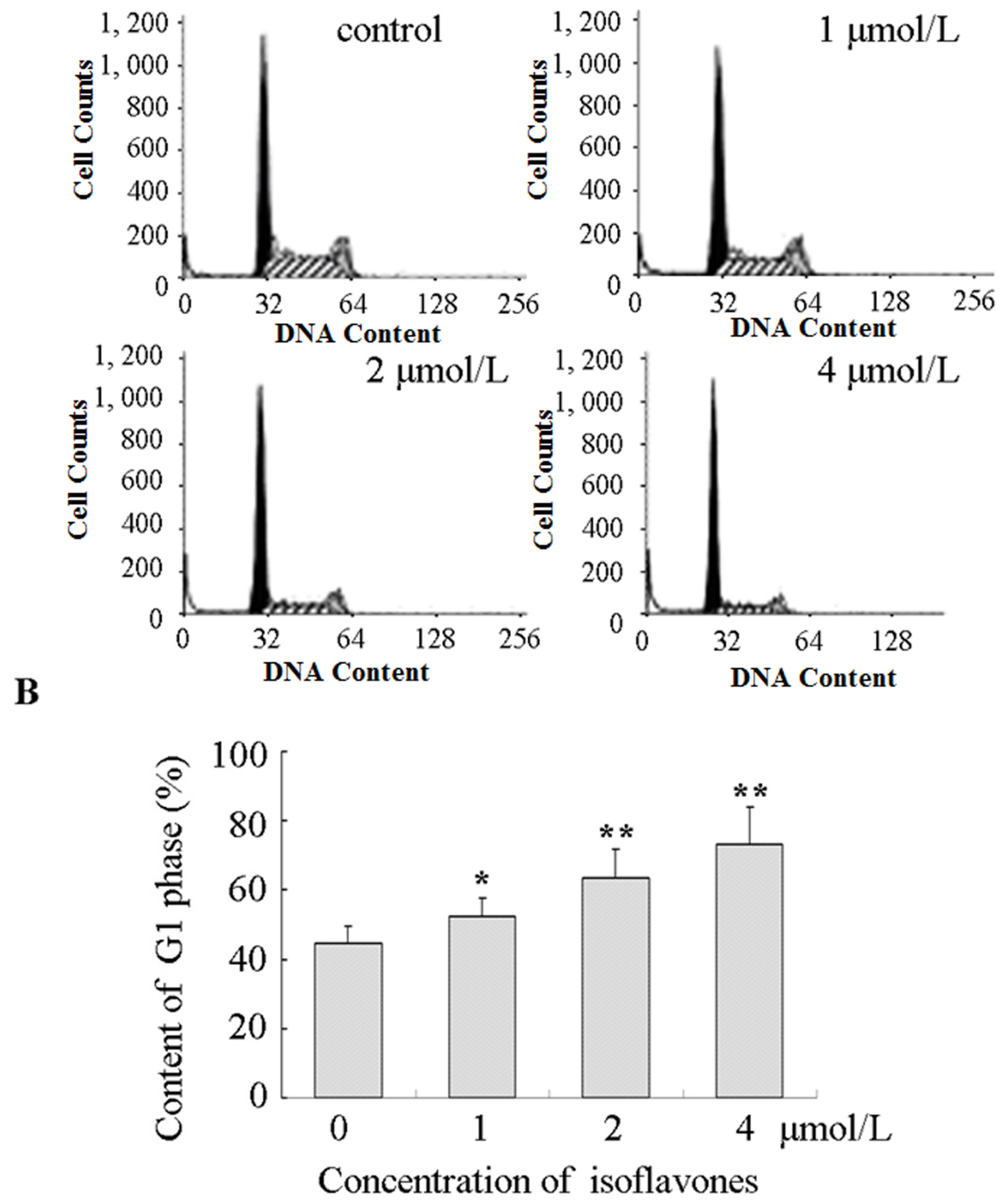

Figure 2: Isoflavones blocked G1/S progression in Y79 cells. A. Cell cycle analysis was performed using propidium iodide staining and flow cytometry. All experiments were repeated at least three times, and a representative example of the DNA content is shown in frequency histograms. B. Cell cycle distribution. Columns: means of triplicate determinations; bars: standard deviations; ${ }^{*} P<0.05 ; * * P$ $<0.01$ compared with respective controls. 
results showed that isoflavones suppressed the mTOR pathway in Y79 cells.

\section{Isoflavones decreased cyclin E1 protein levels through the mTOR pathway}

Cyclin E1 is a positive regulator that controls the transition of cells from G1 to S phase [28]. Numerous data have demonstrated that inhibiting mTOR decreases S6K phosphorylation, with a concomitant decrease in cyclin E1 levels $[22,29]$. We therefore explored the effects of isoflavones on cyclin E1. As shown in Figure $3 \mathrm{~B}$, cyclin $\mathrm{E} 1$ decreased in cells treated with isoflavones. These results showed that isoflavones suppressed mTORmediated accumulation of cyclin E1.

\section{Isoflavones suppressed growth of human retinoblastoma xenografts in vivo}

In order to evaluate the in vivo effect of isoflavones on retinoblastoma growth, a xenograft mouse model of Y79 cells was established and these mice were treated with isoflavones or an equal volume of normal saline (control). As shown in Figure 4A, the mean tumour volume of the control group was larger than that of the isoflavone-treated group from day $18(P<0.05)$. Average tumor volume at 58 days was $308 \pm 66.5 \mathrm{~mm}^{3}$ in the isoflavone treatment group, whereas average tumor volume at 58 days was $603.5 \pm 79.8 \mathrm{~mm}^{3}$ in the control group. Similar results were also observed with tumor weight: The mean tumour weight of the isoflavone-treated group was $0.32 \pm 0.06$ $\mathrm{g}$ and that of the control group was $0.67 \pm 0.09 \mathrm{~g}(P<$ 0.01 , Figure $4 \mathrm{~B})$. These results showed that isoflavones significantly inhibited the growth of xenografted Y79 human retinoblastoma tumours in nude immune-deficient mice.

mTOR activity was assessed in the xenografted tumour tissue. As shown in Figure 4C and 4D, p-mTOR, $\mathrm{p}-\mathrm{S} 6 \mathrm{~K}$ and cyclin-E1 expression was lower in the isoflavone-treated group than in the control group. These results showed that isoflavones also affected mTORmediated accumulation of cyclin E1 in vivo.

\section{DISCUSSION}

Retinoblastoma is the most frequently occurring paediatric ocular cancer [30]. In developing countries, treatment is limited, and if untreated, the disease is always fatal. Long-term survival rates are low, and current chemotherapy causes significant morbidity in paediatric patients, which significantly limits dosing
A

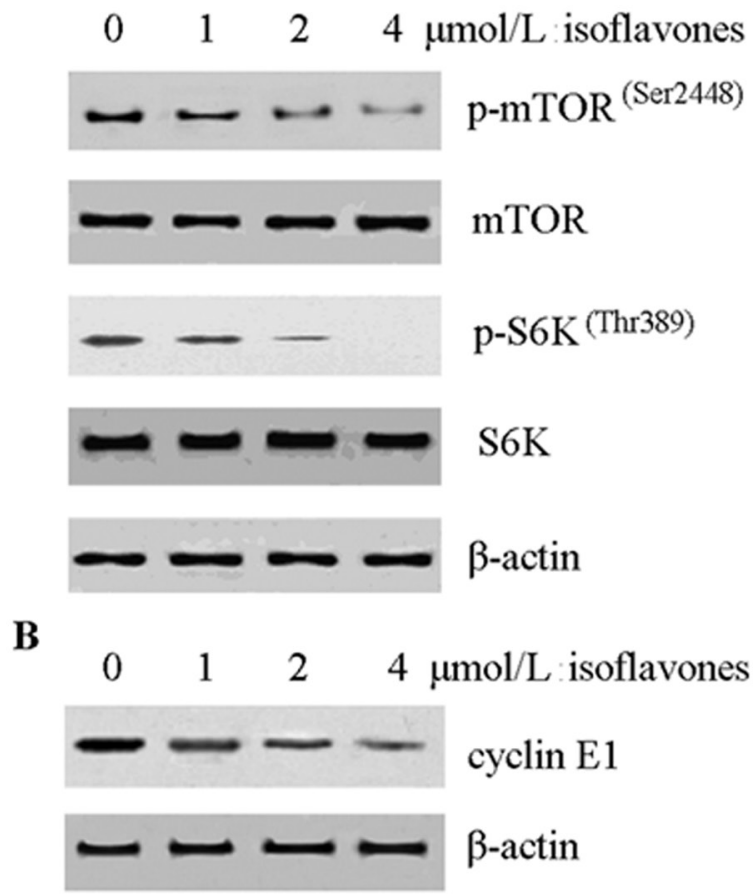

C
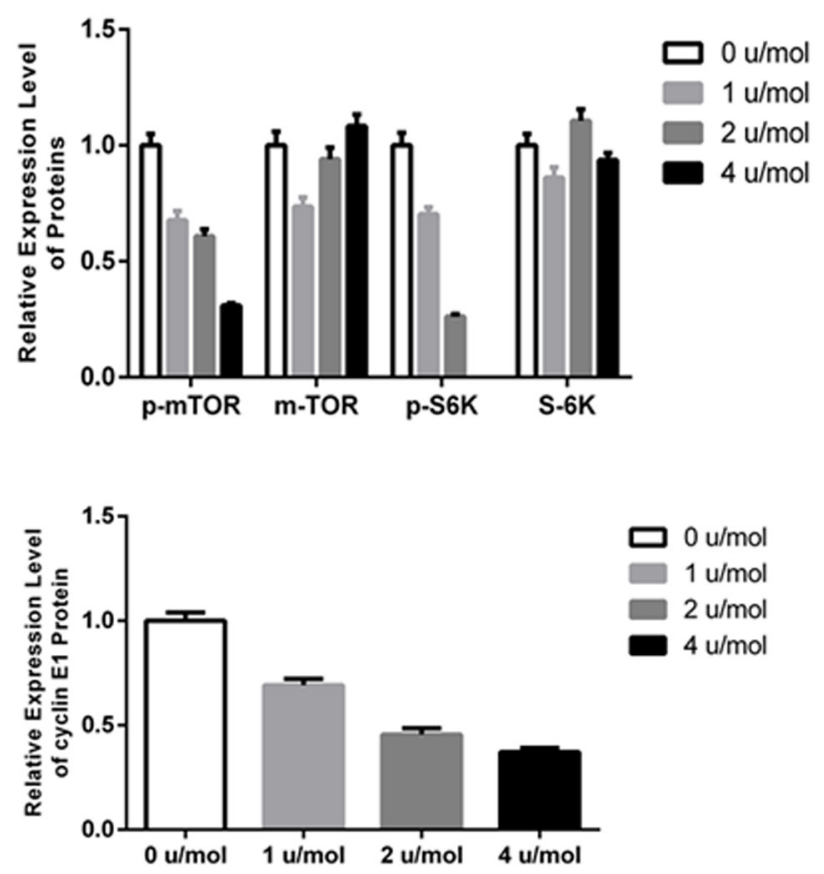

Figure 3: Isoflavones decreased phosphorylation of mTOR and cyclin E1 accumulation. A. Isoflavones inhibited mTOR activity in Y79 cells as shown by western blot analysis. Y79 cells were treated with the indicated concentration of isoflavones for 48 h. B. Isoflavones decreased cyclin E1 protein in Y79 cells as shown by western blot analysis. Y79 cells were treated with the indicated concentration of isoflavones for $48 \mathrm{~h}$. C. Bands of each protein were quantified by densitometric analysis and plotted after normalization against $\beta$-actin. Histogram shows means \pm SEM for three independent sets of experiments. $P<0.05$. 
[31]. The mTOR pathway is one of the most commonly deregulated pathways in cancer and has been implicated in the tumorigenesis of retinoblastoma. Therefore, known inhibitors of this pathway are worth evaluating for the treatment of this disease [32]. Isoflavones, a group of phytoalexins isolated from soybean, have been known to exhibit anticancer activities, and investigations have suggested potent anticancer activities against multiple targets in the phosphatidylinositol-4,5-bisphosphate 3-kinase (PI3K)/Akt/mTOR pathway [33]. For example, isoflavones induced the suppression of $\mathrm{S} 6 \mathrm{~K}$ phosphorylation in oestrogen receptor-positive breast cancer cells [34] and decreased the phosphorylation of Akt and eIF4E proteins in human glioblastoma (U87) cells [35]. In this study, we found that isoflavones showed potent anticancer activity against human retinoblastoma Y79 cells in vitro and in vivo (Figures 1 and 4). Our investigation also elucidated that the isoflavone
A

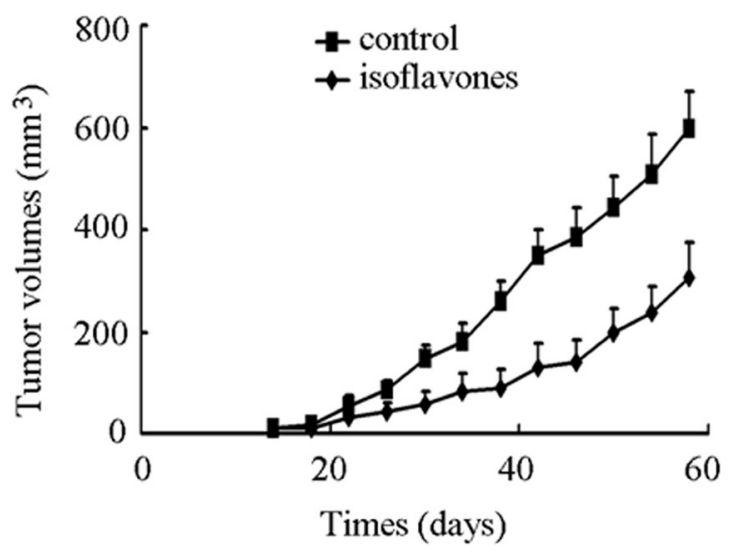

B

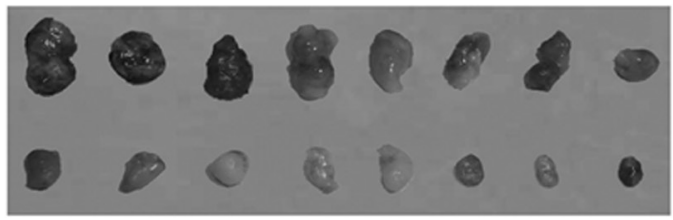

control

isoflavones
C

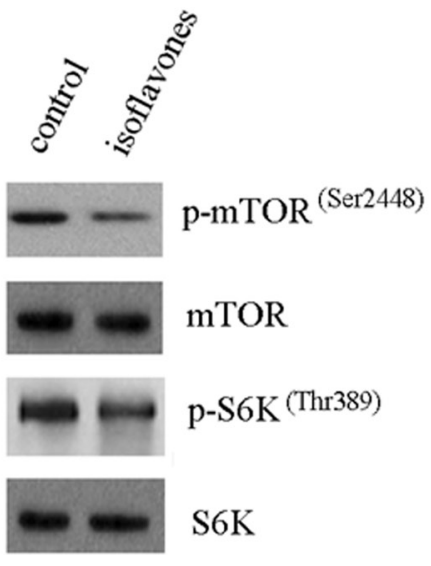

cyclin E1

$\beta$-actin

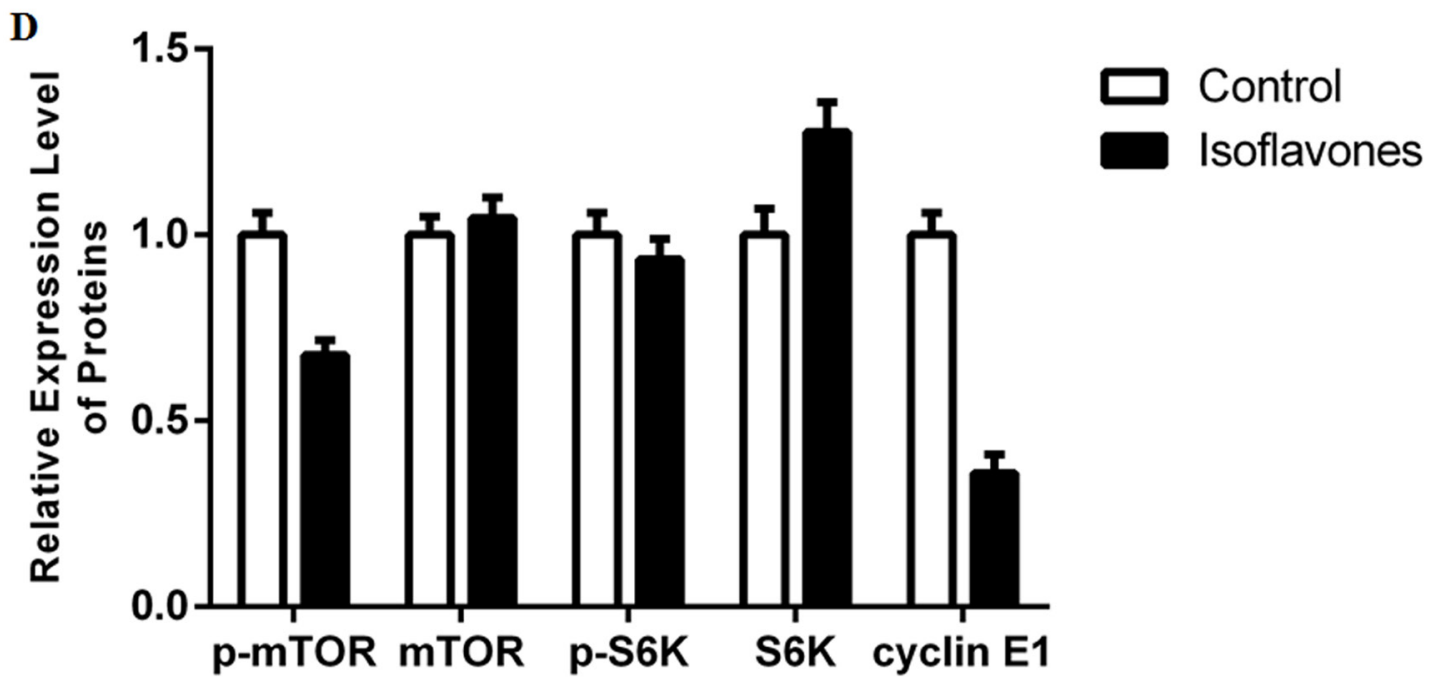

Figure 4: Isoflavones inhibited human retinoblastoma cell growth in a xenograft mouse model by decreasing the phosphorylation of $\mathbf{m T O R}$ and cyclin E1 accumulation. A. Isoflavones inhibited human retinoblastoma cell growth in the xenograft mouse model. B. After euthanisation, the tumours were stripped and photographed. Tumours removed from isoflavone-treated mice are significantly smaller rather than control mice, showing the size difference between the tumours. C. Isoflavones decreased the phosphorylation of mTOR and cyclin E1 accumulation in xenograft tumour tissues. Total protein was extracted from tumour tissues. The indicated protein levels were determined with western blot analysis. D. Bands of each protein were quantified by densitometric analysis and plotted after normalization against $\beta$-actin. Histogram shows means \pm SEM for three independent sets of experiments. $P<0.05$. 
mechanism of action involved blockage of the mTOR pathway and decrease of cyclin E1.

The cell cycle is a vital process by which cells duplicated DNA and divide to produce daughter cells. Dysregulation of cell cycle components may lead to tumour formation [36]. In the present study, our results showed that isoflavones inhibited $\mathrm{G} 1 / \mathrm{S}$ progression in Y79 cells (Figure 2). Cyclins are the key regulators of cell cycle progression. Cyclin E- cyclin-dependent kinase 2 has long been considered an essential master regulator of G1/S progression [37]. Cyclin E1 is a critical target of signals activated during tumorigenesis and is a well-established oncogene. The protein is unstable and is degraded by two distinct pathways involving the ubiquitin-proteasome system [38]; S58 in the N-terminal cluster is phosphorylated by glycogen synthase kinase 3 (GSK-3) [39].

Phosphorylation-triggered ubiquitination has been proposed to be the major pathway regulating the cyclin E1 protein, and mTOR is a critical regulator of GSK3 activity [40]. mTOR has a key regulatory role in cell growth and homeostasis, and inhibition of mTOR is now a novel treatment strategy for several malignancies, either alone or in combination with other approaches [41]. A recent study also showed that cyclin E1 expression could be regulated by the PI3K/Akt/mTOR signalling pathway [29]. In the present study, inhibition of mTOR and downregulation of cyclin E1 occurred in isoflavone-treated human retinoblastoma Y79 cells and in an isoflavonetreated xenograft mouse model (Figures 3, 4C and 4D). This was supported by in vitro and in vivo data showing that isoflavones decreased mTOR phosphorylation, with a concomitant decrease in cyclin E1, which inhibited G1/S progression of human retinoblastoma Y79 cells.

The results in vitro and in vivo showed the isoflavones could inhibit human retinoblastoma Y79 cells. Also there were some other study results demonstrated good promises of isoflavones. Some researchers combined Flt1 peptide with isoflavones, which contributed to exploit this conjugated micelle-like nanoparticles to encapsulate isoflavones. The in vivo biological results showed statistically significant suppression of corneal neovascularization in cauterized corneas of SpragueDawley (SD) rats; the retinal vascular hyperpermeability significantly reduced in diabetic retinopathy model rats [42]. Then another research team use the diabetic retina rats to study isoflavone therapeutic effect. They treated the rats with isoflavones by subcutaneous injection. The results showed that isoflavones could ameliorate the histological changes of diabetic retinopathy in rats, which effects highly resembled a normal retina [43]. Thus, we can draw some preliminary inferences from the results above. Firstly, isoflavones possess good potential druggability. As previously mentioned, the novel combination of Flt 1 peptide and isoflavones was feasible, which could be investigated for further clinical development. Secondly, isoflavones could treat some eye diseases such as diabetic retinopathy. This strongly demonstrated that isoflavones would play its therapeutic effect in eye not only for diabetic related eye disease. Lastly, isoflavones could enter in eyes via blood circulation, which provided another way for drug delivery. And this speciality offers us more possibility to develop its clinical use, especially for its use into eye drops in the future, which could reduce the side effects of general systemic administration. All these results above illustrated the great potential clinical application for isoflavones especially for eye diseases. These also provided us the molecular basis for further eye tumour studies.

In summary, the results of this study suggested that isoflavones reduced cell viability and triggered G1phase blockage by down regulating cyclin E1 protein in human retinoblastoma Y79 cells in vitro and in vivo, mediated through the inhibition of the mTOR pathway. Although further studies are needed, these results have demonstrated the anticancer activities of isoflavones in human retinoblastoma cells and the mechanisms of action involved. Together, these results suggest that isoflavones could be a promising chemotherapeutic agent for retinoblastoma.

\section{MATERIALS AND METHODS}

\section{Reagents and antibodies}

Roswell Park Memorial Institute 1640 medium was purchased from Gibco BRL. Foetal bovine serum was obtained from Life Technologies Corporation. MTT, dimethyl sulfoxide, propidium iodide (PI) and other chemicals were purchased from Sigma Chemical Co. mTOR, phospho-mTOR (Ser2448), p70S6 kinase (S6K), phosphorylated S6K (p-S6K) (Thr389), cyclin D1 and $\beta$-actin antibodies were purchased from Cell Signaling Technology Inc. Genistein was bought from SigmaAldrich Co. LLC.

\section{Cell lines and cell culture conditions}

The human retinoblastoma cell line Y79 was obtained from the American Tissue Type Culture Collection and cultured in Roswell Park Memorial Institute 1640 medium supplemented with $10 \%$ foetal bovine serum, $1 \%$ penicillin and 1\% streptomycin. Y79 cells were grown at $37^{\circ} \mathrm{C}$ in a humidified incubator of $5 \%$ $\mathrm{CO}_{2}$ and $95 \%$ air, as previously described [44]. 


\section{Cell viability}

Cell viability was determined with MTT assay. Briefly, Y79 cells were seeded in 96-well plates at a density of 3,000 cells/well and grown overnight. The next day, isoflavones diluted with growth medium at a full range of concentrations were added to the wells. After incubation for $48 \mathrm{~h}, 10 \mu \mathrm{l}$ MTT ( $5 \mathrm{mg} / \mathrm{ml})$ was added to each well and the plates were incubated at $37^{\circ} \mathrm{C}$ for an additional $4 \mathrm{~h}$. The medium was then removed using a needle and syringe and dimethyl sulfoxide $(100 \mu \mathrm{l})$ was added to each well and pipetted up and down to dissolve the insoluble purple formazan. Finally, the optical density was measured at wavelengths in the range of 500-600 nm using a plate reader (Thermo Fisher Scientific Inc.). The half maximal inhibitory concentration $\left(\mathrm{IC}_{50}\right)$ values were calculated from survival curves as previously described [45]. All experiments were repeated at least three times.

\section{Cell cycle analysis}

Cell cycle analysis was conducted using PI dyes and flow cytometry. Briefly, Y79 cells were seeded in 6 -well plates at a density of $2 \times 10^{5}$ cells/well and grown overnight. The next day, Y79 cells were treated with 0 , 1,2 and $4 \mu \mathrm{mol} / \mathrm{L}$ isoflavones for $48 \mathrm{~h}$. After harvesting and washing, cells were fixed in ice-cold $70 \%$ ethanol at $4^{\circ} \mathrm{C}$ for $24 \mathrm{~h}$. PI ( $\left.400 \mu \mathrm{l}, 50 \mu \mathrm{g} / \mathrm{ml}\right)$ was added for staining for $30 \mathrm{~min}$. Finally, cell cycle phases $(\mathrm{G} 0 / \mathrm{G} 1, \mathrm{~S}$, or $\mathrm{G} 2 / \mathrm{M}$ ) were analysed with flow cytometry using $488 \mathrm{~nm}$ excitation and $620 \mathrm{~nm}$ collection fluorescence. Cell cycle distribution was evaluated using MultiCycle AV software. All experiments were repeated at least three times.

\section{Western blot analysis}

Western blotting was performed as previously described [44]. Briefly, Y79 cells were seeded in 6-well plates at a density of $2 \times 10^{5}$ cells/well and grown overnight. The next day, cells were treated with isoflavones at the $0,1,2$ and $4 \mu \mathrm{mol} / \mathrm{L}$ for $48 \mathrm{~h}$. After harvesting and washing, cells were lysed for 5 minutes in cold radioimmunoprecipitation assay lysis buffer. Equivalent amounts of protein were separated on $8 \%-12 \%$ sodium dodecyl sulphate polyacrylamide gel electrophoresis gel and electrotransferred onto polyvinylidene difluoride (PVDF) membranes (Millipore, USA). PVDF membranes were blocked with $0.05 \%$ Tween 20 and $5 \%$ non-fat dry milk for $2 \mathrm{~h}$ to block nonspecific binding. They were then incubated with primary antibody and appropriate horseradish peroxidase-linked secondary antibodies. $\beta$-actin was used as an endogenous control. Finally, bands of specific proteins on the PVDF membranes were detected with western blotting Luminol reagent (Millipore,
USA). All experiments were repeated at least three times.

\section{Xenograft mouse model}

Specific pathogen-free BALB/c nude mice (weight, $18-20 \mathrm{~g}$ ) were used as a xenograft mouse model. The research was conducted in accordance with the guide from the Review Committee for the Use of Human or Animal Subjects of Sun Yat-sen University and was approved by the Institution of Animal Care and Use Committee at the Institute of Biophysics, Chinese Academy of Sciences (SYXK2013-02). There were eight mice per group (treatment and control). Y79 cell suspension at a cell density of $1 \times 10^{7}$ cells per $0.2 \mathrm{ml}$ was subcutaneously injected into the necks of the mice (6-week-old nude mice). In the control group, normal saline was administered by gavage. In the isoflavone treatment group, isoflavones $(160 \mathrm{mg} / \mathrm{kg})$ were administered in the same manner. The dose of isoflavones was based on previous studies [10]. The size of the subcutaneous tumour was measured on days $3,6,10,14,18,24,30,34,38,42$, 46, 50,54 and 58 . The mice were humanely euthanized on day 58. Tumor volume was determined by direct measurement with callipers at indicated times and calculated according to the following formula: largest tumour diameter ${ }^{2} \times$ second largest tumour diameter $\times 0.5$.

\section{Statistical analysis}

Data were statistically analysed using SPSS Statistics 16.0 software. Results are expressed as mean values \pm standard error. Comparisons were made using one-way analysis of variance followed by Dunnett's test. Significance was determined at a level of $P<0.05$.

\section{Author contributions}

Q. W., H. B., C.-L. H., H.-Y. W., Y.-X. Z., and Y.-D. W. designed the experiments; Q. W., H. B., C.-L. H., Y. Z., X. Z., Y.-X. Z., and Y.-D. W. performed the experiments; and Q. W., H. B., H. W., Y. Z., X. Z., W. Z., Y.-X. Z., and Y.-D. W. contributed to manuscript preparation.

\section{ACKNOWLEDGMENTS}

The authors thank Professor Anlong Xu, Professor Deyin Guo, Professor Chunfeng Qu, Professor Limin Li, Professor Minzhou Guo, Professor Tao Jiang, Professor Yingfang Liu, Professor Jie Ma, Professor Wen Tan, Professor Yuchen Jiao, Professor Chen Wu, Professor Fan Bai, and Dr. Xiaoqiu Ding for their critical comments. 


\section{CONFLICTS OF INTEREST}

The authors declare that there are no conflicts of interest.

\section{GRANT SUPPORT}

This work was supported by grants from Guangdong Province special science and technology (new drug discovery)project (2012A080201002), Guangdong Province Foshan City industry-university-research special project of Gaoming District in 2012 (201211), Guangdong Province Nature Foundation(2016A030313294).

\section{ETHICAL APPROVAL}

The study was approved by the Institution of Animal Care and Use Committee at the Institute of Biophysics, Chinese Academy of Sciences (SYXK2013-02).

\section{REFERENCES}

1. Jin L, Zhang W, Pan H, Li T, Liu B, Zhao J, Wang B. Retrospective investigation of retinoblastoma in Chinese patients. Oncotarget. 2017 May 23. doi: 10.18632/ oncotarget.18174. [Epub ahead of print].

2. Francis JH, Brodie SE, Marr B, Zabor EC, MondesireCrump I, Abramson DH. Efficacy and Toxicity of Intravitreous Chemotherapy for Retinoblastoma: Four-Year Experience. Ophthalmology. 2017; 124: 488-95.

3. Temming P, Viehmann A, Arendt M, Eisele L, Spix C, Bornfeld N, Sauerwein W, Jockel KH, Lohmann DR. Pediatric second primary malignancies after retinoblastoma treatment. Pediatr Blood Cancer. 2015; 62: 1799-804.

4. Qian CN, Mei Y, Zhang J. Cancer metastasis: issues and challenges. Chin J Cancer. 2017; 36: 38.

5. Kan G, He H, Zhao Q, Li X, Li M, Yang H, Kim JK. Functional dissection of the role of UHRF1 in the regulation of retinoblastoma methylome. Oncotarget. 2017; 8:3949739511. doi: 10.18632/oncotarget.17078.

6. Zaheer K, Humayoun Akhtar M. An updated review of dietary isoflavones: Nutrition, processing, bioavailability and impacts on human health. Crit Rev Food Sci Nutr. 2017; 57: 1280-93.

7. Pudenz M, Roth K, Gerhauser C. Impact of soy isoflavones on the epigenome in cancer prevention. Nutrients. 2014; 6: 4218-72.

8. He X, Sun LM. Dietary intake of flavonoid subclasses and risk of colorectal cancer: evidence from population studies. Oncotarget. 2016; 7: 26617-27. doi: 10.18632/ oncotarget.8562.

9. Xiao X, Liu Z, Wang R, Wang J, Zhang S, Cai X, Wu K, Bergan RC, Xu L, Fan D. Genistein suppresses FLT4 and inhibits human colorectal cancer metastasis. Oncotarget.
2015; 6: 3225-39. doi: 10.18632/oncotarget.3064.

10. Bloedon LT, Jeffcoat AR, Lopaczynski W, Schell MJ, Black TM, Dix KJ, Thomas BF, Albright C, Busby MG, Crowell JA, Zeisel SH. Safety and pharmacokinetics of purified soy isoflavones: single-dose administration to postmenopausal women. Am J Clin Nutr. 2002; 76: 1126-37.

11. Shon YH, Park SD, Nam KS. Effective chemopreventive activity of genistein against human breast cancer cells. J Biochem Mol Biol. 2006; 39: 448-51.

12. Peng B, Cao J, Yi S, Wang C, Zheng G, He Z. Inhibition of proliferation and induction of G1-phase cell-cycle arrest by dFMGEN, a novel genistein derivative, in lung carcinoma A549 cells. Drug Chem Toxicol. 2013; 36: 196-204.

13. Tsafa E, Al-Bahrani M, Bentayebi K, Przystal J, Suwan $\mathrm{K}$, Hajitou A. The natural dietary genistein boosts bacteriophage-mediated cancer cell killing by improving phage-targeted tumor cell transduction. Oncotarget. 2016; 7: 52135-49. doi: 10.18632/oncotarget.10662.

14. Akiyama T, Ishida J, Nakagawa S, Ogawara H, Watanabe S, Itoh N, Shibuya M, Fukami Y. Genistein, a specific inhibitor of tyrosine-specific protein kinases. J Biol Chem. 1987; 262: 5592-5.

15. Mahmoud AM, Yang W, Bosland MC. Soy isoflavones and prostate cancer: a review of molecular mechanisms. J Steroid Biochem Mol Biol. 2014; 140: 116-32.

16. Banerjee S, Li Y, Wang Z, Sarkar FH. Multi-targeted therapy of cancer by genistein. Cancer Lett. 2008; 269: 22642.

17. Gu H, Wu W, Yuan B, Tang Q, Guo D, Chen Y, Xia Y, Hu L, Chen D, Sha J, Wang X. Genistein up-regulates miR-20a to disrupt spermatogenesis via targeting Limk1. Oncotarget. 2017; 8:58728-58737. doi: 10.18632/oncotarget. 17637.

18. Geissler EK, Schlitt HJ, Thomas G. mTOR, cancer and transplantation. Am J Transplant. 2008; 8: 2212-8.

19. Bajwa P, Nielsen S, Lombard JM, Rassam L, Nahar P, Rueda BR, Wilkinson JE, Miller RA, Tanwar PS. Overactive mTOR signaling leads to endometrial hyperplasia in aged women and mice. Oncotarget. 2017; 8: 7265-75. doi: 10.18632/oncotarget.13919.

20. Ribierre T, Baulac S. mTOR pathway in familial focal epilepsies. Oncotarget. 2017; 8: 5674-5. doi: 10.18632/ oncotarget.14234.

21. Shaw RJ, Cantley LC. Ras, PI(3)K and mTOR signalling controls tumour cell growth. Nature. 2006; 441: 424-30.

22. Wang YD, Su YJ, Li JY, Yao XC, Liang GJ. Rapamycin, a mTOR inhibitor, induced growth inhibition in retinoblastoma Y79 cell via down-regulation of Bmi-1. Int J Clin Exp Pathol. 2015; 8: 5182-8.

23. Ma KL, Liu J, Wang CX, Ni J, Zhang Y, Wu Y, Lv LL, Ruan XZ, Liu BC. Activation of mTOR modulates SREBP-2 to induce foam cell formation through increased retinoblastoma protein phosphorylation. Cardiovasc Res. 2013; 100: 450-60.

24. Liu M, Qi Z, Liu B, Ren Y, Li H, Yang G, Zhang Q. RY- 
$2 \mathrm{f}$, an isoflavone analog, overcomes cisplatin resistance to inhibit ovarian tumorigenesis via targeting the PI3K/AKT/ mTOR signaling pathway. Oncotarget. 2015; 6: 25281-94. doi: 10.18632/oncotarget.4634.

25. Fujihara S, Kato K, Morishita A, Iwama H, Nishioka T, Chiyo T, Nishiyama N, Miyoshi H, Kobayashi M, Kobara H, Mori H, Okano K, Suzuki Y, et al. Antidiabetic drug metformin inhibits esophageal adenocarcinoma cell proliferation in vitro and in vivo. Int J Oncol. 2014; 46: 2172-80.

26. Gibbons JJ, Abraham RT, Yu K. Mammalian target of rapamycin: discovery of rapamycin reveals a signaling pathway important for normal and cancer cell growth. Semin Oncol. 2009; 36: S3-S17.

27. Hay N, Sonenberg N. Upstream and downstream of mTOR. Genes Dev. 2004; 18: 1926-45.

28. Geng Y, Yu Q, Whoriskey W, Dick F, Tsai KY, Ford HL, Biswas DK, Pardee AB, Amati B, Jacks T, Richardson A, Dyson N, Sicinski P. Expression of cyclins E1 and E2 during mouse development and in neoplasia. Proc Natl Acad Sci U S A. 2001; 98: 13138-43.

29. Oka K, Ohya-Shimada W, Mizuno S, Nakamura T. Upregulation of cyclin-E(1) via proline-mTOR pathway is responsible for HGF-mediated $\mathrm{G}(1) / \mathrm{S}$ progression in the primary culture of rat hepatocytes. Biochem Biophys Res Commun. 2013; 435: 120-5.

30. Nahum MP, Gdal-On M, Kuten A, Herzl G, Horovitz Y, Weyl Ben Arush M. Long-term follow-up of children with retinoblastoma. Pediatr Hematol Oncol. 2001; 18: 173-9.

31. Zheng Q, Zhang Y, Ren Y, Wu Y, Yang S, Zhang Y, Chen $\mathrm{H}, \mathrm{Li}$ W, Zhu Y. Antiproliferative and apoptotic effects of indomethacin on human retinoblastoma cell line Y79 and the involvement of beta-catenin, nuclear factor-kappaB and Akt signaling pathways. Ophthalmic Res. 2014; 51: 109-15.

32. Chakraborty S, Khare S, Dorairaj SK, Prabhakaran VC, Prakash DR, Kumar A. Identification of genes associated with tumorigenesis of retinoblastoma by microarray analysis. Genomics. 2007; 90: 344-53.

33. Ahmad A, Biersack B, Li Y, Kong D, Bao B, Schobert R, Padhye SB, Sarkar FH. Deregulation of PI3K/Akt/mTOR signaling pathways by isoflavones and its implication in cancer treatment. Anticancer Agents Med Chem. 2013; 13: 1014-24.

34. Bratton MR, Martin EC, Elliott S, Rhodes LV, CollinsBurow BM, McLachlan JA, Wiese TE, Boue SM, Burow ME. Glyceollin, a novel regulator of $\mathrm{mTOR} / \mathrm{p} 70 \mathrm{~S} 6$ in estrogen receptor positive breast cancer. J Steroid Biochem Mol Biol. 2015; 150: 17-23.
35. Puli S, Jain A, Lai JC, Bhushan A. Effect of combination treatment of rapamycin and isoflavones on $\mathrm{mTOR}$ pathway in human glioblastoma (U87) cells. Neurochem Res. 2010; 35: 986-93.

36. Champeris Tsaniras S, Kanellakis N, Symeonidou IE, Nikolopoulou P, Lygerou Z, Taraviras S. Licensing of DNA replication, cancer, pluripotency and differentiation: an interlinked world? Semin Cell Dev Biol. 2014; 30: 17480.

37. Hwang HC, Clurman BE. Cyclin E in normal and neoplastic cell cycles. Oncogene. 2005; 24: 2776-86.

38. Koepp DM, Schaefer LK, Ye X, Keyomarsi K, Chu C, Harper JW, Elledge SJ. Phosphorylation-dependent ubiquitination of cyclin E by the SCFFbw7 ubiquitin ligase. Science. 2001; 294: 173-7.

39. Welcker M, Singer J, Loeb KR, Grim J, Bloecher A, Gurien-West M, Clurman BE, Roberts JM. Multisite phosphorylation by Cdk2 and GSK3 controls cyclin E degradation. Mol Cell. 2003; 12: 381-92.

40. Koo J, Yue P, Gal AA, Khuri FR, Sun SY. Maintaining glycogen synthase kinase-3 activity is critical for mTOR kinase inhibitors to inhibit cancer cell growth. Cancer Res. 2014; 74: 2555-68.

41. Faivre S, Kroemer G, Raymond E. Current development of mTOR inhibitors as anticancer agents. Nat Rev Drug Discov. 2006; 5: 671-88.

42. Kim H, Choi JS, Kim KS, Yang JA, Joo CK, Hahn SK. Flt1 peptide-hyaluronate conjugate micelle-like nanoparticles encapsulating genistein for the treatment of ocular neovascularization. Acta Biomater. 2012; 8: 3932-40.

43. Elgayar SA, Eltony SA, Sayed AA, Abdel-Rouf MM. Genistein Treatment Confers Protection against Gliopathy and Vasculopathy of the Diabetic Retina in Rats. Ultrastruct Pathol. 2015; 39: 385-94.

44. Wang YD, Su YJ, Li JY, Yao XC, Liang GJ. Rapamycin, an mTOR inhibitor, induced apoptosis via independent mitochondrial and death receptor pathway in retinoblastoma Y79 cell. Int J Clin Exp Med. 2015; 8: 10723-30.

45. Tao LY, Li JY, Zhang JY. Brazilein, a compound isolated from Caesalpinia sappan Linn., induced growth inhibition in breast cancer cells via involvement of GSK-3beta/betaCatenin/cyclin D1 pathway. Chem Biol Interact. 2013; 206: $1-5$. 